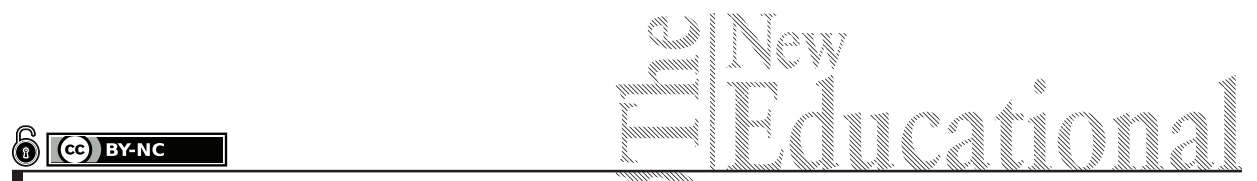

Bożydar L.J. Kaczmarek, Marcin Sfencel

Poland

\title{
Third Mode of Thinking
}

DOI: $10.15804 /$ tner.2018.53.3.24

\begin{abstract}
A number of studies show that both children and adults exhibit difficulties with problem-solving tasks. In fact, only one-third of adults reach the formal operational stage. Coaching such tasks in everybody's language proves to be helpful only if the situation described is close to life events. The presented study confirmed the improvement in the thematic version of the Wason Test both in pupils and university students, albeit being far from spectacular. The authors suggest distinguishing a bounded type of thinking characterized by highly schematic, mechanistic, and automated thinking. They argue that it results both in educational and everyday failures.
\end{abstract}

Keywords: problem-solving, mental schemas, abstract reasoning, bounded thinking.

\section{Introduction}

Piaget $(1926,1972)$ argued for the universality of developmental stages, each consisting of a set of different logical operations. Later studies, however, revealed that abstract reasoning is not an inborn capacity, but must be learned at school. Accordingly, Dasen (1994) revealed that only one-third of adults reach the formal operational stage, while Keating (1979) found that $40-60 \%$ of college students fail at formal operational tasks. This is in contradiction to Piaget's assumption that adolescents at the age of 11-plus reach the formal operational stage, and become able to evaluate the logical validity of verbal propositions without making reference to real-world circumstances. 
Another significant approach to thinking was developed by the "socio-historical" school of psychology (cf., Wertsch, 1981, 1991), of which the best known are Vygotsky $(1962,1978)$ and Luria $(1976,1979)$. This approach assumes that the symbolic products of culture, such as language, other symbolic systems, technical devices and tools, mediate thought and other cognitive processes. An important assumption of that school of thought is that all mental functions of the individual are rooted in social life. In order to study the impact of culture upon reasoning, Vygotsky and Luria (Luria, 1979) conducted field experiments with the inhabitants of nomad camps in Central Asia. They noted that the nomands refused to solve syllogisms and other abstract tasks. They tended to classify objects presented to them in accordance with their functional relations and not logical classes. Accordingly, when asked which of four objects, a tree trunk, a saw, an axe, and a hammer, did not fit with the others, they stated that they all are involved in felling timber. When suggested that wood does not fit in the group of tools they replied that wood is needed to make the handles of hammers and axes.

\section{Research Problem}

Similar misunderstandings can be observed in school children of various ages while solving mathematics problems (Gunbas, 2015; Newman, 1977; Schwarzkopf, 2007). It is often assumed that one reason causing difficulties in solving such problems is the abstract form of such tasks (Williams, 2015). Therefore, a number of authors suggest that depicting an abstract mathematics problem in a well-known social situation should help pupils to solve it. Yet, it was observed that dressing up mathematics tasks as word problems, often led to additional linguistic difficulties (Cooper, \& Harries, 2005; Gerofsky, 1996; Vilenius-Tuohimaa, Aunola, \& Nurmi, 2008). Certainly, the necessity for coping with unfamiliar terms may create difficulties, but it is quite plausible that it is caused not only by wording but also by the situations described. Hence, Palm (2006) advocated making such description more realistic. All the same, the concordance between events described in a given mathematics task and the out-of-school situation appears to be insufficient for many pupils to provide a solution.

A previous study by the authors showed that couching mathematics tasks in everyday language describing well-known authentic out-of-school situations really made it possible to solve them. Typical situations encountered while doing shopping were utilized there. The study included 152 secondary school pupils: 71 girls and 81 boys, aged 13, who had already learned the rules of parsing the mathematical formula. A detailed account of the study was presented in another paper (Kaczmarek, Stencel, \& Łukasiewicz, et al., 2018), so only the results will be presented. 
Statistical analysis data confirmed the hypotheses that the traditional algebraic form creates difficulties, while the thematic form of the task makes solving the problem possible. Accordingly, the percentage of correct responses increased from 57.2 (in the case of algebraic equations) to 84.3 in their thematic versions. This confirms the assumption that the acquired cognitive schemas, which include a set of context-sensitive rules, make it possible to solve the problem.

\section{Research Methodology}

\section{Research General Background}

Another well-known example of difficulties with abstract reasoning is the Wason Selection Test. A subject is given four cards, all of which have a letter on one side and a number on the other side. The subject can see the four facing sides as follows - A-D 4 and 7. The examiner explains that the following rule applies to these four cards: "If a card has a vowel on one side, then it has an even number on the other side". In a number of studies it was found that the correct choice of cards, i.e., A and 7, was made by only about $10 \%$, while the majority of participants selected either card A alone or card A and 4. It requires a little consideration to figure out that card four does not porovide an answer if the rule is falsified, since the card with an even number may have either a vowel or a consonant. On the other hand, card A must have an even number on the reverse, and card 7 should not have a vowel (Wason, 1966).

Griggs and Cox (1982) presented the same task in the "social context". Subjects were presented with four cards labelled: drinking beer, drinking coke, 16 years of age, and 22 years of age. The participants were given the following instruction:

These four cards represent persons in a bar, and each card has their drink on one side and their age in years on the other. You are a policeman, whose duty it is to check if a person drinking beer is over the age of 20 . Select the card or cards that you need to turn over to determine whether or not the law has been violated.

It turned out that the subjects' performance improved substantially after the scenario of people drinking in a bar and a policeman enforcing the law were introduced. Such a dramatic improvement in the subjects' performance was labelled as "thematic content effect".

The authors explain their findings in terms of a memory-cueing hypothesis, which assumes that recalling past experience with the content of a given problem 
enables subjects to solve it. Interestingly, a similar explanation was offered by Wason (1977) himself. He stated with some regret that "the critical appreciation of falsification is aroused not by invoking a calculus, but by assimilation to more mundane experience" (p. 132). On the other hand, Cosmides (1989) argues that performance on the drinking-age problem is improved because it reflects a "social contract" situation.

\section{Presented study}

The Wason Test was administered to 65 secondary school pupils (33 girls and 32 boys, aged 13) and to 45 (32 women and 13 men) second-year extramural university students of psychology (mean age 31 ). Participation was voluntary and anonymous, and no time limit was imposed.

\section{Instrument and Procedures}

The participants were given two separate test sheets including both versions of the Wason Test. At the initial stage, they were asked to solve the original test and then its thematic version.

\section{Data Analysis}

The percentages of correct responses were calculated for both versions separately.

\section{Research Results}

Some improvement in the second thematic version of the test could be noted in the pupils. They gave $1.5 \%$ of correct responses in the original version, while the score in the thematic version was higher, but it reached only $18.4 \%$. It might be assumed that difficulties with solving the word problem may be due to the lack of personal experience. After all, 13-year-old youngsters are not frequent bar customers.

In order to clarify that dubiety, we performed the same study with university students. As expected, the students scored better on both versions, but the number of correct responses in solving the thematic version was still not very high, despite the fact that it was double the number of scores they obtained in the first version, ratio: $15.5 \%-35.5 \%$. This means that almost two-thirds of the examined students were not able to correctly solve the thematic version of the Wason Task. This is in 
agreement with the observations of some other authors (e.g., Evans, 1995; Manktelow, \& Evans, 1979; Pretz, Naples, \& Sternberg, 2003).

\section{Discussion}

An experiment performed by Kaminski, Sloutsky and Heckler (2008) seems to contradict our findings. The authors stated that learning based on abstract examples resulted in better transfer of knowledge than learning based on concrete examples. Yet, their experiment has two significant shortcomings: first, the instructions given to the participants were very simple, in contradistiction to the quite complex instructions given by the teacher in a classroom; second, the transfer pertained to immediate and prompted effects (Jones, 2009). De Bock, Verschaffel, Van Dooren, Deprez and Roelens (2011) replicated Kaminski's experiment, and concluded that the partiticipants actually learned only to map symbols and combination rules.

The above-conclusion indicates a very important problem. Pupils are taught to memorize a set of rules and procedures without understanding their underlying principles. In effect, they tend to perceive mathematics problems as puzzle-like tasks to be solved arithmetically, without taking into account their content. This finds confirmation in the well-known age-of-the-captain nonsensical problem, which runs as follows: "There were 26 sheep and 10 goats on a ship. How old was the captain?" Many studies revealed that most children from various cultures gave the answer 36.

The protocol of answers given by one of the second-grade pupils is very instructive in this respect. It runs as follows:

There are 125 sheep and 5 dogs in a flock. How old is the shepherd?"

Protocol: $\ldots 125+5=130 \ldots$ this is too big, and $125-5 \ldots 120$ is still too big $\ldots$ while $\ldots 125: 5=25 \ldots$ that works ... I think the shepherd is 25 years old (Reusser, 1986, p. 25).

The above protocol confirms the observations of other authors that children tend to treat mathematics as a set of artificial rules to be used for combining numbers. Similar results were obtained by Puchalska and Semadeni (1987), who gave 7-8-year-old Polish children a number of nonsensical problems. The majority of the examined children gave wrong answers but a few of them, especially the younger ones, protested that the task was unsolvable. This is in agreement with 
the observations by Radatz (1984), who notes that during problem solving, school beginners with little mathematical experience concentrate on stories, while older ones concentrate on numbers, and try to solve the problem in accordance with procedures acquired in the classroom.

Such an approach is linked to the belief that maths tasks are well-defined problems whose solution requires only a straightforward calculation in contrast to life problems (Pretz, Naples, \& Sternberg, 2003). However, life problems are not so much ill-defined as complex. The life problems are complex for two reasons. First, we are usually faced with many alternations, and second, we do not have enough information to make really rational decisions. In many real life situations we react in a subconscious, automatic way. Reactions of that kind are believed to stem from the ways in which our homoid ancestors used to act while confronted with dangers existing in prehistorical epochs (e.g., Goleman, 2007). With regard to those behaviours, Evans (1984) distinguished two modes of thinking: type I (intuitive) and type II (reflective). Type I is believed to be fast, subconscious, contextualized, associative, and automatic, while type II is regarded as slow, conscious, abstract, controlled, and rule-based (cf. also Evans, \& Stanovich, 2013; Stanovich, \& West, 2000). Social psychologists often use the terms "cognitive schemas" and "heuristics" to specify ready-made mental shortcuts for making decisions and judgements under uncertaintly, i.e., thinking in terms of system I (Kahneman, 2011; Tversky, \& Kahneman, 1974).

Attempts to define, clearly and specifically, two types of thinking (concrete and abstract) to a considerable degree result from a rationalistic 'scientific' mode of perceiving mental work, and a belief in a strictly experimental approach to study. Yet, as argued by Johnson-Laird (1980), such an approach gives rise to errors since it is based on rules elaborated by the medieval scholastic logics and not the original classical principles. It also neglects the habitual biases manifested by participants in experiments. Hence, in real life situations, we often come across simplistic habitual, and mechanistic reasoning in which acquired cognitive schemas are used in an automated way. The above-mentioned factors pose limitation on reasoning. Therefore, we propose the term bounded thinking with reference to the theory of "bounded rationality" developed by Simon $(1957,1970)$.

Bounded thinking is closely linked to the cognitive dissonance as it is frequently used in reaction to perceived inconsistencies between the actions, beliefs, attitudes, and principles of a particular person. In the case of bounded thinking, however, the dissonance concerns not only our own actions but also the actions of others. This may be best observed in the followers of political parties who reconceptualize those actions of party leaders which violate the proclaimed values. Such rational- 
ization makes it possible to maintain a stable world view and to preserve positive self-esteem. In this respect, it is also close to motivated reasoning (Kunda, 1990). Such a change of perception was described as a third method of resolution of the cognitive disonance by Leon Festinger (1957), an originator of that theory.

The above considerations show that psychologists, philosophers and cognitive scientists concentrate on reasoning closely linked to problem solving. Much less attention is given to the way in which people think in everyday situations. We all know how difficult it is to persuade somebody to change their view upon a matter they deeply believe to be true. This suggests that really effective thinking requires dynamic schemas that would undergo changes in accordance with the arising circumstances (cf., Groesser \&Schaffernicht, 2012). And that is the main problem with bounded thinking since it is based on stiff and unchangeable mental schemas. As a rule, these schemas have been created on the basis of the personal experience of a given person and proved to work in many everyday situations. No wonder, any reasoning that contradicts those models meets with strong rejection.

Reliance on personal experience could be also observed in our studies on understanding proverbs (unpublished data). Difficulties of young children who had limited life experience were the most pronounced. At the same time, adolescents attending vocational schools were able to explain the meaning of a proverb, but again it was closely linked to their life experience. Accordingly, a 17-year-old youngster gave the following explanation of the proverb: Strike while the iron is hot: "Well, if you have a girl ... you should snow her, kiss her, talk to her while she is young".

\section{Conclusions}

It is often assumed that the mechanistic automated mode of reasoning results from the way mathematics is taught. It seems, however, that this is a much broader problem. The mechanistic automated mode of thinking appears to be characteristic not only of children but also of adults. This mode of thinking is characterized by highly schematic, habitual, mechanistic, and simplistic reasoning. It is deeply grounded in personal experience and stable mental schemas.

The difference between type II (rational) reasoning and the bounded mode of thinking is clear, yet the distinction of type I and bounded thinking may be confusing, we will, therefore, ellaborate on it. Type I reasoning is subconscious, intuitive, and common to all cultures, while bounded thinking is conscious, contra-intuitive, culturally bounded, and grounded in common sense logic. In 
addition, bounded thinking is based on beliefs, attitudes, and biases, hence, it is difficult to implement changes.

That type of thinking is closely linked to the use of a restricted code distinguished by Bernstein (2000). As indicated in another study (Kaczmarek \& Markiewicz, 2003), the restricted code is characterized not only by simplified grammar, but also by the specific use of words, and above all, it is closely linked to a simplified mode of thinking. In consequence, its users display a simplified world image, overconfidence, belief in one truth, and lack of insight.

Unfortunately, contemporary schooling does not help in overcoming that type of thinking. First, due to the ways of teaching, second, to the use of standardized tests in assessing learning outcomes. It is worth pointing out that learning by memorizing facts and technical details concerns not only science but also the humanities. Pupils are required to memorize dates and names of important persons while leaving aside the significance and consequences of those facts. In effect, they become similar to efficient robots or computers, capable of fast calculations and performing various complicated operations without seeing the sense of all those procedures.

This calls for a need to create such forms of training that would make it possible to overcome the natural tendency to use well-learned automated mental schemas in solving every-day problems, and acquire the capability of abstract thinking.

\section{Acknowledgements}

This study was supported by an internal grant of the authors' University.

\section{References}

Bernstein, B. (2000). Pedagogy, symbolic control and identity. Theory, research, critique. Lanham: Rowman \& Littlefield.

Cooper, B., \& Harries, T. (2005). Making sense of realistic word problems: Portraying working class "failure" on a division with remainder problem. International Journal of Research \& Method in Education, 28, 147-169.

Cosmides, L. (1989). The logic of social exchange: Has natural selection shaped how humans reason? Studies with the Wason selection task. Cognition 31, 187-276.

Dasen, P. (1994). Culture and cognitive development from a Piagetian perspective. In W.J. Lonner and. R.S. Malpass (Eds.), Psychology and culture (pp. 145-149). Boston, MA: Allyn and Bacon.

De Bock, D., Verschaffel, L., Van Dooren, W., Deprez, J., \& Roelens, M. (2011). Abstract or concrete examples in learning mathematics? A replication and elaboration of Kaminski, 
Sloutsky, and Heckler' study. Journal for Research in Mathematics Education, 42(2), 109-126.

Evans, J. (1984). Heuristic and analytic processes in reasoning. British Journal of Psychology, 75: 451-468.

Evans, J.S.B.T. (1995). Relevance and Reasoning. In S.E. Newstead, \& J.S.B. T Evans (Eds.), Perspectives on thinking and reasoning. Essays in honour of Peter Wason (pp. 147-171). Hillsdale: Lawrence Erlbaum Associates.

Evans, J., \& Stanovich, K.E. (2013). Dual-process theories of higher cognition: Advancing the debate. Perspectives on Psychological Science, 8, 223-241.

Festinger, L. (1957). A theory of cognitive dissonance. Stanford: Stanford University Press.

Gerofsky, S. (1996). A linguistic and narrative view of word problems in mathematics education. For the Learning of Mathematics, 16(2), 36-45.

Goleman, D. (2007). Social intelligence: The new science of human relationships. London: Arrow Books.

Griggs, R.A. \& Cox, J.R. (1982). The elusive thematic-materials effect in Wason's selection task. British Journal of Psychology, 73, 407-420.

Groesser, S.N., Schaffernich M. (2012 ). Mental models of dynamic systems: taking stock and looking ahead. System Dynamics Review, 28(1), 46-68.

Gunbas, N. (2015). Students' mathematics word problem-solving achievement in a computer-based story. Journal of Computer Assisted Learning, 31, 78-95.

Jones, M.G. (2009). Examining surface features in context. Journal for Research in Mathematics Education, 40, 94-96.

Johnson-Laird, P.N. (1980). Mental models in cognitive science. Cognitive Science, 4, 71-115.

Johnson-Laird, P. (2010). Mental models and human reasoning. Proceedings of the National Academy of Sciences, 107(43), 18243-18250.

Kaczmarek, B.L.J., \& Markiewicz, K. (2003). The real nature of the restricted code. In B.D. MacQueen, \& M. Pachalska (Eds.), Society as text in the thought of Richard Harvey Brown (pp. 75-85). Wrocław: Continuo Publishing House.

Kaczmarek, B.L.J., Stencel, M., \& Łukasiewicz, J. (2017). Mathematical reasoning and the form of a task. Horyzonty Psychologii, 7, 7-18.

Kahneman, D. (2011). Thinking, fast and slow. New York: Farrar, Strauss, Giroux.

Kahneman, D. \& Frederick, S. (2002). Representativeness revisited: Attribute substitution in intuitive judgment. In T. Gilovich, D. Griffin, \& D. Kahneman (Eds.). Heuristics and biases: the psychology of intuitive judgment (pp. 103-119). Cambridge: Cambridge University Press.

Kaminski, J.A., Sloutsky, V.M., \& Heckler, A.F. (2008). The advantage of abstract examples in learning math. Science, 320, 454-455.

Keating, D. (1979). Adolescent thinking. In J. Adelson (Ed.), Handbook of adolescent psychology (pp. 211-246). New York: Wiley.

Koedinger, K.R., Alibali M.W., Mitchell J., \& Nathan M.J. (2008). Trade-offs between 
grounded and abstract representations: Evidence from algebra problem solving. Cognitive Science 32, 366-397.

Luria, A.R. (1976). Cognitive development: Its cultural and social foundations. Cambridge, Harvard University Press.

Luria, A.R. (1979). The making of mind. A personal account of Soviet psychology. Cambridge: Harvard University Press.

Manktelow K.I., \& Evans J.S B.T. (1979). Facilitation of reasoning by realism: Effect or non-effect? British Journal of Psychology, 70, 477-488.

Newman, M. (1977). An analysis of sixth-grade pupils errors on written mathematical tasks, Research in Mathematics Education in Australia 1, 239-258.

Palm, T. (2006). Word problems as simulations of real-world situations: a proposed framework. For the Learning of Mathematics, 26(1), 42-47.

Piaget, J. (1926). The language and thought of the child. London: Routledge.

Piaget, J. (1972). The Psychology of intelligence. Totowa: Littlefield.

Pretz, J.E., Naples, A.J., \& Sternberg, R.J. (2003). Recognizing, defining, and representing problems. In J.E. Davidson, \& R.J. Sternberg (Eds.), The psychology of problem solving (pp. 3-30). Cambridge: Cambridge University Press.

Puchalska, E., \& Semadeni, Z. (1987) Children's reactions to verbal arithmetical problems with missing, surplus or contradictory data. For the Learning of Mathematics, 1(3), 9-16.

Radatz, H. (1984) Schwierigkeiten der Anwendung Arithmetischen Wissens am Beispiel des Sachrechnens. In: J.H. Lorenz, (Ed.) Lernschwierigkellw Forschung und Praxis. Untersuchungen zum Mathematikunterricht (pp. 17-29) Bielefeld: Universitat Bielefeld.

Reusser, K. (1986) Problem solving beyond the logic of things. Textual and contextual effects on understanding and solving word problems. Paper presented at the Annual Meeting of the $70^{\text {th }}$ American Educational Research Association, San Francisco, April 16-20.

Schwarzkopf, R. (2007). Elementary modeling in mathematics lessons: The interplay between real-world knowledge and mathematics structures. In W. Blum, P.L. Galbraith, H-W. Henn, \& M. Niss (Eds.), Modelling and applications in mathematics education (pp. 209-216). New York: Springer.

Simon, H.A. (1957). Models of man, social and rational: Mathematical essays on rational human behavior in a social setting. New York: John Wiley and Sons

Simon, H.A., \& Newell, A. (1970). Human problem-solving: the state of the theory in 1970, American Psychologist, 26, 145-159.

Stanovich, K.E. (2011). Rationality and the reflective mind. New York: Oxford University Press.

Stanovich, K.E., West, R.F. (2000). Individual differences in reasoning: Implications for the rationality debate? Behavioral and Brain Sciences, 23, 645-726.

Tversky, A., \& Kahneman, D. (1974). Judgment under uncertainty: Heuristics and biases. Science, 185, 1124-1130.

Vilenius-Tuohimaa, P.M., Aunola, K., \& Nurmi, J.-E. (2008). The association between 
mathematical word problems and reading comprehension. Educational Psychology, 28, 409-426.

Vygotsky, L.S. (1962). Thought and language. Cambridge: MIT Press.

Vygotsky, L.S. (1978). Mind in society: The development of higher psychological processes. Cambridge, : Harvard University Press

Wason, P. (1966). Reasoning. In B.M. Foss (Ed.), New horizons in psychology, vol. 1, (pp. 135-151). Harmondsworth: Penguin.

Wason P.. (1977). The theory of formal operations: A critique. In B. Gerber (Ed.), Piaget and knowing (pp. 119-135). London: Routledge and Kegan Paul.

Wertsch, J.V. (Ed.) (1981). The concept of activity in Soviet psychology. Armonk: Sharpe.

Wertsch, J.V. (1991). Voices of the mind. A sociocultural approach to mediated action. Cambridge: Harvard University Press.

Williams, J. (2015). Alienation in mathematics education: critique and development of neo-Vygotskian perspectives. Educational Studies in Mathematics, 21(1), 59-73. 